\title{
Outcome of Cranioplasty Done within and Beyond 2 Months after Decompressive Craniectomy for Traumatic Brain Injury
}

\author{
Khongbantabam Vyas ${ }^{1}$, Khaidem Mani Singh ${ }^{2}$ \\ ${ }^{1}$ Department of Surgery, Jawaharlal Institute of Medical Science (JNIMS), Imphal, India. \\ ${ }^{2}$ Department of Radiodiagnosis, Jawaharlal Institute of Medical Science (JNIMS), Imphal, India.
}

\section{ABSTRACT}

\section{BACKGROUND}

Cranioplasty although a simple elective neurosurgical procedure is burdened by considerable morbidity. The timing of doing cranioplasty and a good outcome remains a topic of much debate. We wanted to compare the outcome of doing cranioplasty within (early) and beyond (late) 2 months after decompressive craniectomy for traumatic brain injury.

\section{METHODS}

The study was carried out in a tertiary care hospital. A 5-year retrospective study of patient records was analysed. Consecutive series of traumatic brain injury patients who underwent cranioplasty after decompressive craniectomy from a tertiary care hospital operated by a single neurosurgeon, were studied. Data was analysed using SPSS version 21, IBM. Associations of categorical variables were compared using chisquare test and of continuous variables by using unpaired 2 -tailed Student t-test.

\section{RESULTS}

Altogether 90 patients were identified who had undergone cranioplasty after decompressive craniectomy for traumatic brain injury and were grouped into early (within 2 months; 44 patients) and late (beyond 2 months; 46 patients). Cranioplasty operative time was significantly shorter in the early (59.39 mins) than the late (77.28 mins) with a $\mathrm{P}$ value of 0.001 . Infection rates were significantly higher in the early $(4.55 \%)$ than late $(0 \%)$, with $\mathrm{P}$ value 0.144 . Other complication rates were postoperative haematoma ( $0 \%$ early, $2.17 \%$ late, $\mathrm{P}=0.325)$, hydrocephalus $(0 \%$ early, $6.52 \%$ late, $\mathrm{P}=0.085)$, sunken brain ( $0 \%$ early, $4.35 \%$ late, $\mathrm{P}=0.162)$, and bone graft resorption (0\% early, $2.17 \%$ late, $\mathrm{P}=0.325)$. These differences were not statistically significant though.

\section{CONCLUSIONS}

Early cranioplasty performed within 2 months of decompressive craniectomy has better outcome in the form of reduced hospital stay, decreased cost, and fewer complications.

\section{KEY WORDS}

Traumatic Brain Injury, Decompressive Craniectomy, Outcome, Cranioplasty
Corresponding Author: Dr. Khongbantabam Vyas, Associate Professor, Department of Surgery, Jawaharlal Nehru Institute of Medical Sciences, (JNIMS), Imphal, Manipur, India. E-mail: kvyas98@yahoo.com

DOI: $10.14260 /$ jemds/2021/152

How to Cite This Article:

Vyas K, Singh KM. Outcome of cranioplasty done within and beyond 2 months after decompressive craniectomy for traumatic brain injury. J Evolution Med Dent Sci 2021;10(10):711-714, DOI: 10.14260/jemds/2021/152

Submission 27-10-2020,

Peer Review 15-01-2021,

Acceptance 21-01-2021,

Published 08-03-2021.

Copyright (C) 2021 JEMDS. This is an open access article distributed under Creative Commons Attribution License [Attribution 4.0 International (CC BY 4.0)] 


\section{BACKGROUND}

Decompressive craniectomy (DC) is generally performed to treat high intracranial pressure associated with severe traumatic brain injury (TBI) for last few decades. Survival rates were found to increase after DC. ${ }^{1}{ }^{2}$ There is a wide uniform consensus across the globe that after DC, cranial defects need to be reconstructed in the form of cranioplasty which can be autologous or by using synthetic materials. DC is a measure taken up as a lifesaving procedure though it entails another surgery, namely cranioplasty, at a later stage to replace the bone back. Cranioplasty is more or less mandatory to protect the brain, giving back the contour to the skull, to prevent the brain from retracting inside, and to prevent alteration of cerebrospinal fluid (CSF) dynamics. ${ }^{3}$ Objective of this study was to find out the difference in outcome of patients undergoing cranioplasty within and beyond 2 months after DC for TBI.

\section{METHODS}

We did a retrospective analysis of all consecutive cases of TBI who underwent decompressive craniectomy and eventual cranioplasty over a period of 5 years (2011 - 2015). The study was approved by hospital review board. Recruitment of cases was done by the principal investigator who is the neurosurgeon, from the hospital records such as case sheets, discharge summary \& follow up sheets. Cases were divided into two cohorts, early and late, depending on whether cranioplasty was conducted within or beyond 2 months respectively, after DC for TBI. Early cranioplasty is defined as the time interval of 2 months or less between the decompressive craniectomy and cranioplasty, whereas late / delayed cranioplasty is defined as the time interval of more than 2 months between the DC and cranioplasty. Factors which used to decide appropriate time for individual patients were overall clinical status, a healed craniectomy scar, and ability to bear cost of hospital stay.

Patients who had undergone DC for causes other than trauma, like (brain tumour, skull bone tumours, haemorrhagic stroke and ischemic infarcts) were excluded from the study. Informed consents were obtained for operations from patient or patient's close relative, before every operation on a prescribed consent form. Data was collected from the hospital records of each patients. The following parameters were noted: Age at cranioplasty, sex, indications for DC, location of craniectomy, unilateral or bilateral, time interval between DC and cranioplasty, type of cranioplasty material (autologous or artificial graft), type of fixators used (titanium plate and screws / silk materials), postoperative complications (blood clot, hydrocephalus, infections, bone resorption, use of drains at graft harvesting site, duration of hospital stay (number of post-operative days after cranioplasty), operation time.

All the patients were also evaluated for any post-operative surgical complications such as re-operation, infections, hydrocephalus, post-operative haematoma, sunken brain and bone resorption. The decision of reoperation was decided on the basis of clinical conditions i.e., deterioration from the preoperative Glasgow Coma Score (GCS) level. This was confirmed by evaluating with computed tomography (CT scan) for the presence of haematoma which can be epidural, subdural or underlying contused brain with or without midline shift. Infections were considered to be present at the surgical site when there is clinical evidence of erythema, pain, fever, fluid collections or discharge at the harvesting site. Patients who had discharge from the cranial wound site were subjected to removal of cranioplasty flap. Gram staining, culture and antimicrobial sensitivity tests were done for samples and treatment followed with intravenous antibiotics. Bone resorption was defined as decrease in the size of bone flap at the harvesting site that could be palpated. Hydrocephalus was defined with clinical presentation of increased intracranial pressure such as headache associated with vomiting or with altered mental status and radiological evidence of ventricular dilatation based on the CT imaging and treatment in the form of CSF diversion.

\section{Statistical Analysis}

Demographic, clinical and outcome data were compared for the early and late cohorts using SPSS (Statistical Package for Social Science, version 21, IBM). Data was recorded in numbers, proportions and percentages. Comparisons between categorical variables were done using chi-square test. Associations between continuous variables were compared using the unpaired 2-tailed Student t-test. Significance was considered at $95 \%$ level.

\section{RESULTS}

We identified 90 patients who were subjected to cranioplasty for traumatic brain injury between 2011 to 2015. The mean age for all patients was 43.7 years (range 20 - 67 years). The mean time to cranioplasty was 9.6 weeks (range $1-40$ weeks). The median time to cranioplasty was 8 weeks. The mean follow-up time after doing cranioplasty for all patients was 3.2 weeks (range 1 - 12 weeks).

For 44 patients in the early cohort, cranioplasty was done within 2 months of decompressive craniectomy and for 46 patients in the late cohort it was done beyond 2 months of decompressive craniectomy. There was no statistically significant difference in age, sex, type of graft used, material used, and presence of shunt. The operative time was significantly shorter in the early cohort group (59.3 mins early, 77.2 mins late, $\mathrm{P}=0.001$ ). Mean follow up time was almost same in between the two cohorts (early cohort 2.18 weeks / late cohort 2.61 weeks) and this difference was not statistically significant $(\mathrm{P}=0.084)$. In comparing the complication rates between early cohort $4.6 \%$ and late cohort $15.2 \%$, it revealed no significant difference. Post-operative complication like haematoma (early $0 \%$, late $2.17 \% ; \mathrm{P}=0.325$ ), hydrocephalus (early $0 \%$, late $6.52 \%$; $=0.085$ ), sunken brain (early $0 \%$, late $4.35 \% ; \mathrm{P}=0.162$ ), bone resorption (early $0 \%$, late 2.17 $\% ; \mathrm{P}=0.325$ ) did not reveal any significant statistically. Rate of infection was more in (early $4.55 \%$, late $0 \%$; $\mathrm{P}=0.144$ ) but still no statically significant.

Comparison of the complications rate between the early and late cranioplasty revealed no significant difference. The rates of infections were more in the early cohort groups whereas other rates of development of postoperative 
haematoma, hydrocephalus, sunken brain, bone resorption were higher in the late cohort group, but there was no difference statistically. All the patients were discharged on $4^{\text {th }}$ post op day except for 4 cases. There was 1 reoperation due to development of extradural haematoma whose recovery period was of 6 weeks duration and the other 3 case underwent shunting. Follow up period were at $1^{\text {st }}$ week, 1 month, 3 months and subsequent 6 months.

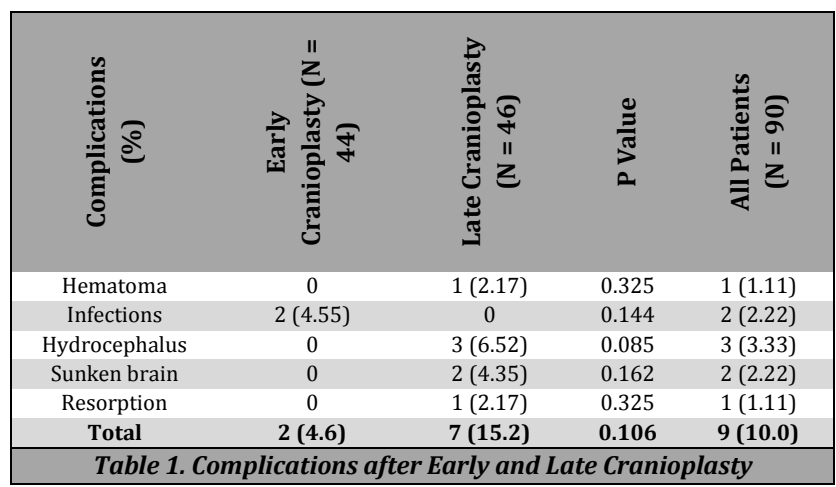

\begin{tabular}{|c|c|c|c|}
\hline Characteristics & $\begin{array}{c}\text { Early } \\
\text { Cranioplasty } \\
(\mathrm{N}=44)\end{array}$ & $\begin{array}{c}\text { Late } \\
\text { Cranioplasty } \\
(\mathrm{N}=46)\end{array}$ & $\begin{array}{c}\text { P- } \\
\text { Value }\end{array}$ \\
\hline Mean age, years ( \pm SD) sex type, $N \%$ & $41.75(13.4)$ & $45.61(12.5)$ & \multirow[t]{2}{*}{0.212} \\
\hline Male & $38(86.36)$ & $42(91.30)$ & \\
\hline Female & $6(13.63)$ & $4(8.70)$ & 0.456 \\
\hline Mean time to cranioplasty, weeks ( \pm SD) & $4.39(1.2)$ & $14.61(4.3)$ & \\
\hline Cranioplasty type, $\mathrm{N}(\%)$ autologous & $44(100)$ & $44(95.7)$ & 0.162 \\
\hline Artificial & $0(0)$ & 2( & \multirow{2}{*}{0.673} \\
\hline Use of cranial drain, $\mathrm{N}(\%)$ & $41(93.2)$ & 44 & \\
\hline Mean operative time, minutes $( \pm S D)$ & $59.39(7.3)$ & $77.28(9.9)$ & 0.001 \\
\hline Mean follow-up, weeks $( \pm$ SD) & $2.18(0.7)$ & $2.61(1.2)$ & 0.084 \\
\hline $\begin{array}{r}\text { Table 2. Comparison Char } \\
\text { (within } 2 \text { Months) and } L \\
\text { Months) afte }\end{array}$ & $\begin{array}{l}\text { etween Early } \\
\text { Cranioplasty } \\
\text { C for Trauma }\end{array}$ & $\begin{array}{l}\text { Cranioplasty } \\
\text { (Beyond } 2\end{array}$ & \\
\hline
\end{tabular}

\section{DISCUSSION}

The reconstruction of skull defects is ideally for protective as well as for cosmetic purposes. The factors which are important in the outcome of the patients are mainly on age, GCS score at the time of admission and pupillary status. In this retrospective data analysis of patients undergoing cranioplasty following decompressive craniectomy for traumatic brain injury the complication rates of early cohort study (within 2 months) were not statistically different from the late cohort study (after 2 months). The overall complication rates of this study was $10 \%$ (probably due to less sample size), which is comparatively lower at about one third of those found in previous literature.4,5,6 This study reveals development of postoperative haematoma in late cohort (2.17 $\%)$ study. Complication rates of infection was observed in the early cohort ( $4.55 \%$ ) in contrast to other studies where it was more in late cranioplasty. ${ }^{7}$ It is generally believed that early cranioplasty is associated with infections and late cranioplasty is usually associated with bone resorption.7,8,9

In this study ( $2.17 \%$ ) bone resorption was seen in the late cohort. There is literature which shows bone resorption rate after cranioplasty have high incidence in children.8,10 In children less than 18 years of age undergoing delayed cranioplasty, there is threefold risk of bone resorption. ${ }^{11,12}$ This study due to less number of cases and having no patients less than 20 years of age, bone resorption was seen in $2.17 \%$ (delayed cranioplasty). This can be deduced to the thinner skulls in children, plus the continuing growth of the cranium which result in increasing size of the defect whereas there is a decrease size of the bone flap. The development of hydrocephalus in the late cohort group up to $6.52 \%$ might be accounted by the slow progression of symptomatic hydrocephalus ${ }^{7}$. There is no development of symptomatic hydrocephalus in the early group. Sunken brain (4.35\%) was seen in the late cohort group which could be attributed to alteration in CSF dynamics ${ }^{3}$. In case of safety; performing cranioplasty after decompressive craniectomy within 2 months is nevertheless safe as performing after 2 months. The overall complication rates were $10 \%$, in which haematoma, hydrocephalus, sunken brain, bone resorption combined make it to $15.2 \%$ in delayed group whereas it is $4.6 \%$ (infections) in early group.

After decompressive craniectomy to perform cranioplasty within 2 months may offer some advantage to performing cranioplasty after 2 months. In this study operative time was significantly shorten to 59 mins (early cohort), 77 mins (late cohort), $\mathrm{P}=0.001$. This could be attributed to difficulty in dissecting the skin flap and fitting the bone flap. Another advantage is the recovery time to hasten rehabilitation programme after early cranioplasty. This study is slightly hampered by the smaller number of patients to show the complication rates between early and late group. Cases were reviewed from a data of 5 years, from a single institution and from a single neurosurgeon in a state having a population of 2.5 million. To summarise, other publications have the advantage of doing the study in a large series of patients. The data which is depicted in this study shows complication rates mainly of infections, postoperative haematoma, hydrocephalus and bone resorption which is of very less number. There is no optimal timing to perform cranioplasty. Nevertheless, what is striking is bone resorption which is observed in delayed cranioplasty.

We can conclude that there is no optimal timing which gives better result in performing cranioplasty, though it is noted that bone resorption is more in the late cohort group, in addition to decrease operation time in the early group. The outcome of cranioplasty has been discussed because of complications like infections and development of late onset hydrocephalus. Earlier it was reported that early cranioplasty associated with great morbidity which is due to insufficient scalp conditions and unresolved trauma insult. But there are certain views coming up (within 1 month after DC) permitting a good dissection plane without causing additional complications such as infections, brain tissue injury subdural hygroma. Delayed cranioplasty does not seem to lower infections. It was emphasized that performing cranioplasty as soon as the swelling subsides and when the site is sunken. ${ }^{13,14,15}$ There are studies showing that cranioplasty gives a better neurological outcome. It is a well-known fact that there are alterations in the CSF dynamics after decompressive craniectomy. ${ }^{3,16}$ It is generally believed that early cranioplasty is associated with infections and late cranioplasty is usually associated with bone resorption. ${ }^{17,18,19}$ There are literature which shows infections does not have significant relations in early and late cranioplasty. ${ }^{20,21,22}$ Cranioplasty done as soon as the clinical conditions of the patients permits, or when there is resolution of the brain 
swelling (proven by CT scan ) or when the margin of the bone viewable. The overall 90 cases were collected from a data period of 5 years which can be less in numbers, while other publications have large number of cases over a longer period of time. This lowers the cost of the patients and thereby reduces the hospital stay duration. It results in decreased hospital stay and also the overall cost factor.

\section{CONCLUSIONS}

Cranioplasty is a relatively simple, safe and easy surgical procedure which is done on an elective basis. Rates of infections, postoperative haematoma, hydrocephalus, sunken brain and bone resorption are not affected by doing cranioplasty within 2 months. When it is delayed operative time, and cost factors increase. Outcome of doing early cranioplasty is more favourable. Early cranioplasty prevented brain from sinking inside the cranial cavity, it restored CSF dynamics, reduced hospital stays, and minimised hospital cost.

Data sharing statement provided by the authors is available with the full text of this article at jemds.com.

Financial or other competing interests: None.

Disclosure forms provided by the authors are available with the full text of this article at jemds.com.

\section{REFERENCES}

[1] Zanaty M, Chalouhi N, Starke RM, et al. Predictors of infections following cranioplasty: a retrospective review of a large single center study. Scientific World Journal 2014:356042

[2] Huang YH, Liao CC, Yang KY, et al. Is timing of cranioplasty following post traumatic craniectomy related to neurological outcome? Int J Surg 2013;11(9):886-90.

[3] Winkler PA, Stummer W, Linke R, et al. Influence of cranioplasty on postural blood flow regulation, cerebrovascular reserve capacity and cerebral glucose metabolism. J Neurosurg 2000;93(1):53-61.

[4] Chun HJ, Yi HJ. Efficacy and safety of early cranioplasty at least within 1 month. J Craniofac Surg 2011;22(1):203-7.

[5] Beauchamp KM, Kashuk J, Moore EE, et al. Cranioplasty after post injury decompressive craniectomy: is timing of the essence. J Trauma 2010;69(2):270-4.

[6] Gooch MR, Gin GE, Kenning TJ, et al. Complications of cranioplasty following decompressive craniectomy: analysis of 62 cases. Neurosurg Focus 2009;26(6):E9.

[7] Piedra MP, Nemecek AN, Ragel BT. Timing of cranioplasty after decompressive craniotomy for trauma. Surg Neurol Int 2014;5:25.

[8] Matsuno A, Tanaka H, Iwamuro H, et al. Analyses of the factors influencing bone graft infection after delayed cranioplasty. Acta Neurochir (Wien) 2006;148(5):53540.
[9] Piedra MP, Thompson EM, Selden NR, et al. Optimal timing of autologous cranioplasty after decompressive craniectomy in children. J Neurosurg Pediatr 2012;10(4):268-72.

[10] Bhat AR, Kirmani AR, Nimarii F, et al. Sunken brain and scalp flap syndrome following decompressive extracraniectomy. The Indian Journal of Neurotrauma 2011;8(2):105-8.

[11] Aarabi B, Hesdorffer DC, Ahn ES, et al. Outcome following decompressive craniectomy for malignant swelling due to severe head injury. J Neurosurg 2006;104(4):469-79.

[12] Chibbaro S, Di Rocco F, Mirone G, et al. Decompressive craniectomy and early cranioplasty for the management of severe head injury: a prospective multicenter study on 147 patients. World Neurosurg 2011;75(3-4):558-62.

[13] Tasiou A, Vagkopoulos K, Georgiadis I, et al. Cranioplasty optimal timing in cases of decompressive craniectomy after severe head injury: a systematic literature review. Neurosurgery 2014;1(4):107-11.

[14] Albanese J, Leone M, Alliez JR, et al. Decompressive craniectomy for severe traumatic brain injury: evaluation of the effects at one year. Crit Care Med 2003;31(10):2535-8.

[15] Liang W, Xiaofeng Y, Weiguo L, et al. Cranioplasty of large cranial defect at an early stage after decompressive craniectomy performed for severe head trauma. J Craniofac Surg 2007;18(3):526-32.

[16] Schuss P, Vatter H, Marquardt G, et al. Cranioplasty after decompressive craniectomy: the effect of timing on postoperative complications. J Neurotrauma 2012;29(6):1090-5.

[17] Sahuquillo J, Arikan F. Decompressive craniectomy for the treatment of refractory high intracranial pressure in traumatic brain injury. Cochrane Database Syst Rev 2006;(1):CD003983.

[18] Grant GA, Jolley M, Ellenbogen RG, et al. Failure of autologous bone-assisted cranioplasty following decompressive craniectomy in children and adolescents. J Neurosurg 2004;100(Suppl 2):163-8.

[19] Chang V, Hartzfeld P, Langlois M, et al. Outcomes of cranial repair after craniectomy. J Neurosurg 2010;112(5):11204.

[20] De Bonis P, Frassanito P, Mangiola A, et al. Cranial repair: how complicated is filling a hole? J Neurotrauma 2012;29(6):1071-6.

[21] Jiang JY, Xu W, Li WP, et al. Efficacy of standard trauma craniectomy for refractory intracranial hypertension with severe traumatic brain injury: a multicenter, prospective, randomized controlled study. J Neurotrauma 2005;22(6):623-8.

[22] Moreira-Gonzalez A, Jackson IT, Miyawaki T, et al. Clinical outcome in cranioplasty: critical review in long-term follow-up. J Craniofac Surg 2003;14(2):144-53. 